\title{
Beyond memorization: an intermediate-level paleontology activity that integrates anatomy, ecology, and macroevolutionary theory using trilobites
}

\author{
Michelle M Casey ${ }^{1 *}$ and Bruce S Lieberman ${ }^{1,2}$
}

\begin{abstract}
Here we present a stand-alone, upper level undergraduate laboratory exercise that integrates organismal ecology and evolutionary concepts and minimizes the need for student memorization. This laboratory seeks to integrate both anatomical and conceptual content into paleontology lab pedagogy by demonstrating how taxon-specific anatomical information are the fundamental data by which scientists evaluate big picture questions related to the study of macroevolution and ecology. Real specimen photos are provided to familiarize students with a relatively limited suite of anatomical terms and taxonomic detail while allowing schools lacking large paleontology collections to participate in specimen-based inquiry. A matching exercise requires students to assign various trilobite morphologies to their interpreted ecological niches, thus reinforcing the students' new anatomical knowledge and helping students to distinguish between primary and secondary interpretation of scientific evidence. The use of trilobites as a macroevolutionary case study introduces students to questions still being actively investigated by scientists and provides an effective refutation of creationist arguments. By deemphasizing systematics and highlighting intriguing patterns from the recent published literature, this laboratory hopes to promote paleontology as a vibrant and relevant field, and avoid the misconception that paleontologists are simply stamp collectors, intent on naming and categorizing fossils. We hope that the broad implementation of this laboratory exercise will generate the data necessary to evaluate the validity of this approach and its ease of use in the classroom.
\end{abstract}

Keywords: Macroevolution; Trilobita; Volatility; Ecological niches; Mass extinction

\section{Learning goals and pedagogy}

We have developed a trilobite laboratory for college students; here we describe aspects and elaborate on the background and pedagogical philosophy behind the formulation of this lab. The complete version of the lab itself and the key are available as a pdf downloadz at the end of this article (Additional files 1 and 2). However, since the pedagogical and background elements pertaining to the development of the lab are not provided therein, we felt it important to present this information in the context of a broader discussion about the best way to teach paleontology and evolution to undergraduates. The trilobite lab we developed is intended

\footnotetext{
* Correspondence: mcasey@ku.edu

1 Biodiversity Institute, Natural History Museum, University of Kansas, Lawrence, KS 66045, USA

Full list of author information is available at the end of the article
}

for an upper level undergraduate paleontology course enrolling mainly sophomores and juniors who have already taken historical geology or its equivalent but may also be appropriate for introductory college biology or advanced high school biology courses provided that concepts such as geologic time, phylogeny, and trace fossils are familiar to students. It aims to comprise an exercise for one week in what would be a multi-week lab, though it can also serve as a standalone exercise as well. This lab will be particularly helpful to those institutions that lack a large teaching collection by providing color photographs of museum specimens. Students may find previous exposure to phylogenetic methods and terminology helpful in completing this laboratory exercise. The learning goals for this lab are: 1) to familiarize students with the anatomy and terminology relating to trilobites; 
2) to give students experience identifying morphologic structures on real fossil specimens, not just diagrammatic representations; 3 ) to highlight at the grand scale the evolutionary history and ecology of Trilobita; 4) to outline scientific reasoning and present paleontology as an exciting, modern discipline; and 5) to introduce students to the study of macroevolution in the fossil record using trilobites as a case study.

The Teaching Paleontology in the 21st century website (On the Cutting Edge - Professional Development for Geoscience Faculty 2013) compares and contrasts two organizational schemes for the teaching of paleontology. The taxon approach covers phyla sequentially. The benefit of this approach is that it provides in-depth coverage of all taxa, so that students learn the same types of information about all of the disparate groups. This is also the way that many textbooks and sources are organized. The drawbacks of such an approach are that they can potentially be dry, they emphasize memorization, and fail to teach or develop problem solving or critical thinking skills. A secondary byproduct of this teaching approach is that students may fail to see paleontology as a relevant and important discipline. By contrast, the conceptual model organizes the course around a series of big picture concepts within paleontology which tends to generate greater student interest and enthusiasm. However, by the same token, coverage of the taxonomy and morphology of individual groups may be too cursory for students to gain a true appreciation of each fossil clade. Given that each of these two approaches has strengths and weaknesses we have tried to combine them in the present laboratory exercise by mixing the traditional taxon approach and the conceptual framework approach. We accomplish this by covering information on the anatomy and ecology of the group while also delving into macroevolutionary concepts the group elucidates. In particular, this lab teaches the basic anatomy and ecology of Trilobita and then requires the students to apply that new knowledge to an exercise on macroevolution. We aim by reinforcement to inculcate anatomical terminology via the lab, as retention and understanding of anatomy is still critical for tackling modern problems in paleontology. Ultimately, it is critical to integrate both anatomical and conceptual content into paleontology lab pedagogy. One mode to attain this, and the tack followed in the present lab, involves demonstrating how taxon-specific anatomical information are the fundamental data by which scientists evaluate big picture questions related to the study of macroevolution.

Proper undergraduate paleontology education is crucial in an age where debates over the teaching of evolution continue to make headlines (Weissert 2013). Padian (2010) argued that teaching macroevolution is an effective way to counter creationist arguments that are typically more focused on microevolution. In particular, Padian (2010) suggested that by increasing the coverage of macroevolutionary concepts at the college level not only is greater student interest generated but a greater understanding of the fallacy of creationism is attained. Padian (2008) also demonstrated that an emphasis on macroevolution is often lacking in upper level biology, evolution, and paleontology textbooks. By combining a discussion of macroevolutionary theory with the latest published research on trilobite pattern and process, this lab aims to follow Padian's $(2008,2010)$ precepts.

\section{Trilobite morphology and specimen photographs}

This laboratory exercise contains a number of color photographs of actual fossil specimens that highlight the diversity of trilobite morphologies found in the fossil record. These photographs allow students at colleges and universities lacking large paleontological or teaching collections to gain an appreciation for the beauty and startling variety of trilobite forms. Several sections of the laboratory focus on the inferred function of anatomical structures. For example, the part of the General Anatomy section dealing with limbs uses a combination of real specimens with soft tissue preservation (Figure 1A) and diagrammatic representations (Figure 1B) to contrast the differences in walking leg and gill arch morphology. The exercise asks students to first identify the gill arch by circling it on the photo provided and then asks the student: "What was the gill's function?" This question assesses whether or not students gained the appropriate knowledge from the preceding paragraph and provides context for the following questions. Next the lab asks: "How did the gill's feathery construction help it perform this function?" This is intended to evaluate understanding and lead the students to consider the impact of increased surface area on the extraction of oxygen from seawater. Finally the laboratory asks: "What factors constrain the placement of the gills? For instance, would gills placed under the walking leg be more or less effective? Why?" This question requires students to evaluate the structure's placement in terms of factors that would affect its ability to function. The Ecological Niches section of the laboratory, discussed in detail below, provides another example of the pairing of anatomy with a discussion of inferred function.

These discussions of form and function give students a sense of what trilobites were like as living animals rather than treating them as inert objects. By replacing the lengthy descriptions of each trilobite order (a more traditional approach) with this morphological variety approach, we are deemphasizing the role of memorization. Reducing an exercise's reliance on memorization as a means of assessment is important because a student's negative perception of a course as memorization-based 
A

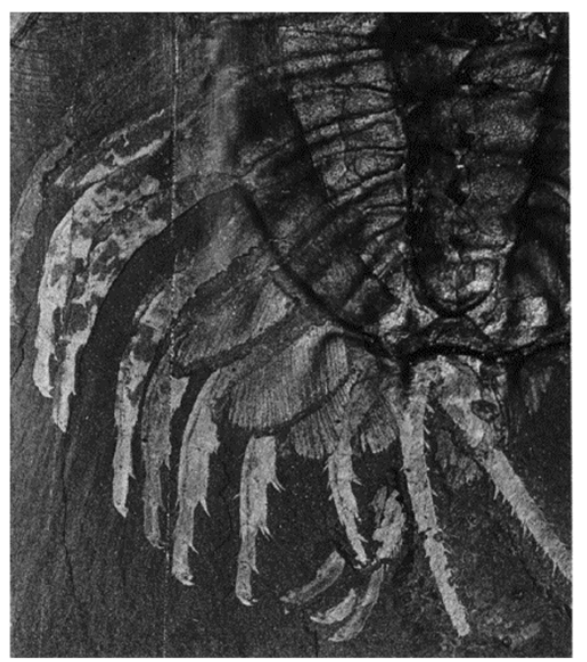

B

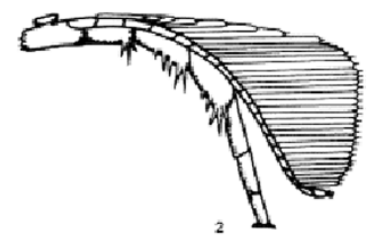

Figure 1 Trilobite biramous limb morphology. A) Close up of Middle Cambrian Olenoides serratus from Treatise on Invertebrate Paleontology, used with permission. B) Limb reconstruction from the Treatise on Invertebrate Paleontology, used with permission.

can decrease a student's interest in and perceived value of the course material (Vermunt and Vermetten 2004). These changes in student affect can lead to decreased learning, persistence, and effort on the part of the student (McConnell and van der Hoeven Kraft 2011). DeHaan (2005) summarizes the recommendations of numerous reports on science education reform by stating that science education should focus, "less on vocabulary and facts that students memorize, and more on students' understanding of scientific concepts and how those concepts fit together in a framework of knowledge about a subject". In addition to the benefits of decreased memorization listed above, it behooves us as paleontologists to present our discipline to future generations of potential scientists in the best possible light. An over-reliance on systematics and taxonomic memorization gives students the false impression that paleontologists are stamp collectors only interested in naming and classifying organisms and squanders the opportunity to paint a vivid picture of past life.

In spite of the negative aspects of memorization-based activities discussed above, it is important that undergraduate students learn a small amount of basic anatomy and its associated terminology. A short treatment of basic anatomy ensures that the same types of information are covered for each taxonomic group studied (On the Cutting Edge - Professional Development for Geoscience Faculty 2013) and develops a common language with which to discuss the ecology and evolutionary history of the group. This laboratory exercise first asks students to identify important features of trilobite anatomy in small groups using an un-labeled trilobite diagram. The lab then uses a combination of labelled diagrams and color photographs of real specimens to teach students basic trilobite morphology and its associated terminology (Figures 2 and 3). Students are asked to reflect on their own list of anatomical features. Students have the opportunity to comment on how their own list of features is or is not consistent with the list of accepted anatomical traits and what aspects of the nomenclature they found surprising. Students are then asked to identify anatomical structures on photographs of two trilobite species, Phacops milleri (Figure 2) and Isotelus iowensis (Figure 3). The goal in repeating the activity with multiple taxa is to help students train their eyes to recognize homologous morphological features across groups with varied appearances and repeat the application of the new terms learned. Next, the students are asked to apply their new anatomical vocabulary by writing a brief description of any one of the trilobites figured. Students are then asked to identify the trilobite described by their neighbor's observations. Finally, follow up questions give students the opportunity to reflect on the difficulty of identifying a specimen from a written description and asks them what they would add to their original description given their new perspective on the importance of thorough observations. In other sections specific questions are added to guide students through the types of observations expected. When asked to describe the eyes of trilobites students are given a list of things to consider including: whether the eye is schizochroal or holochroal; the size of the eye; the position of the eye; and the field of vision the trilobite may have had (in which directions can the trilobite see?).

The combination of learning anatomical vocabulary and developing observational skills will allow students to use published taxonomic descriptions to make 


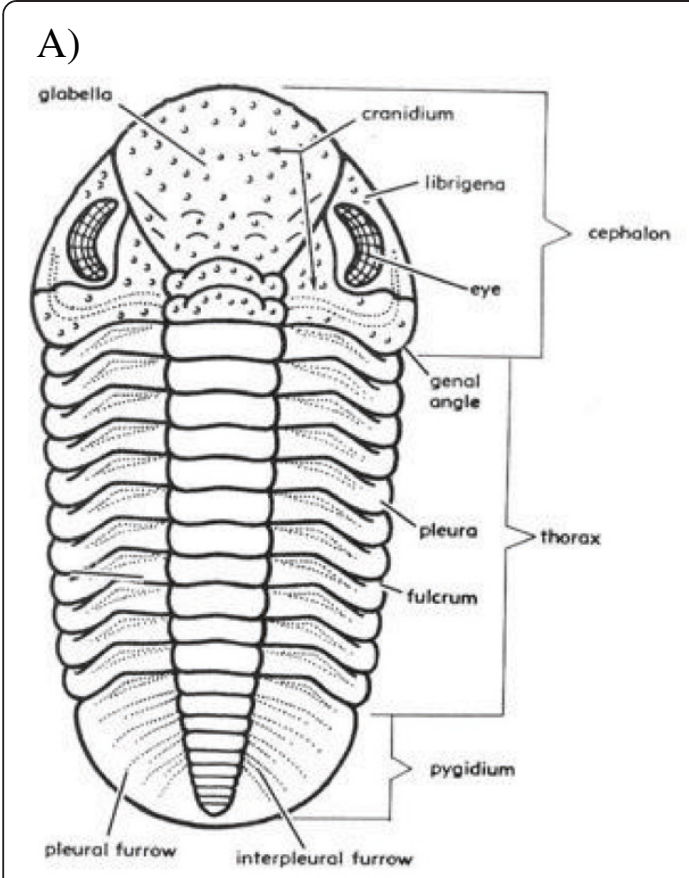

B)

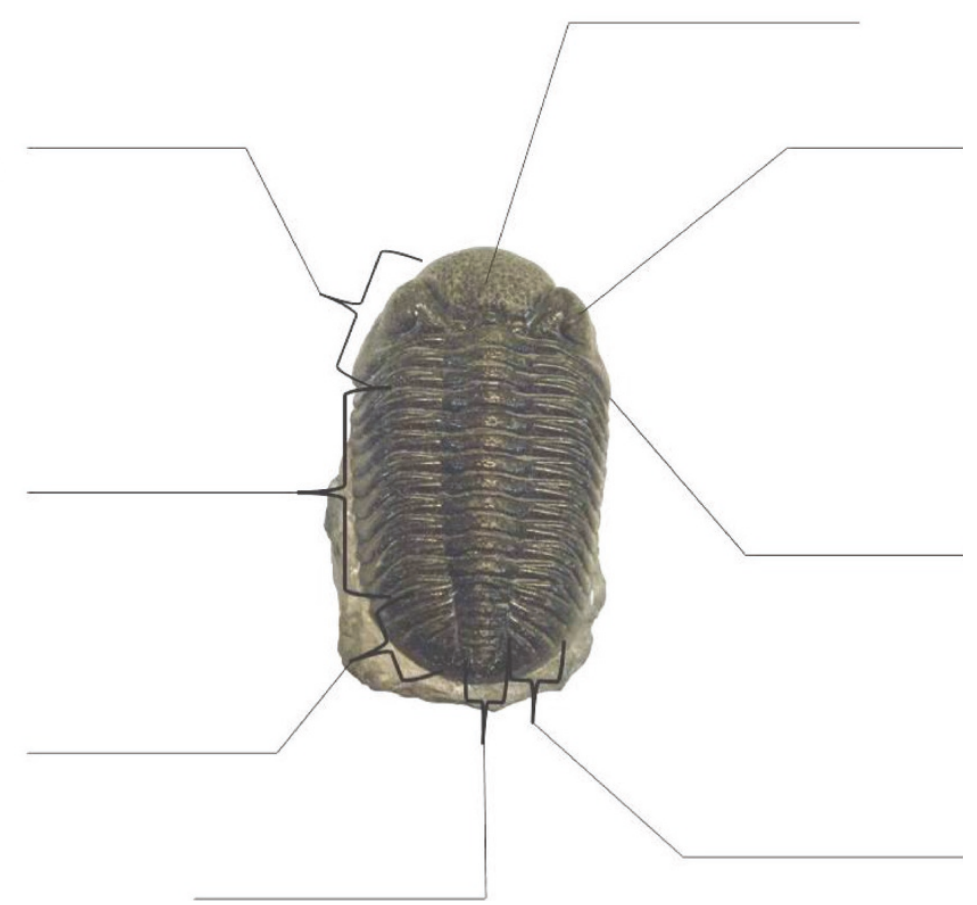

Figure 2 Diagram and specimen photo used to convey basic anatomy. A) Diagram of Phacops from the Treatise on Invertebrate Paleontology, used with permission. B) Photo of Phacops milleri specimen University of Kansas Museum of Invertebrate Paleontology, on exhibit.

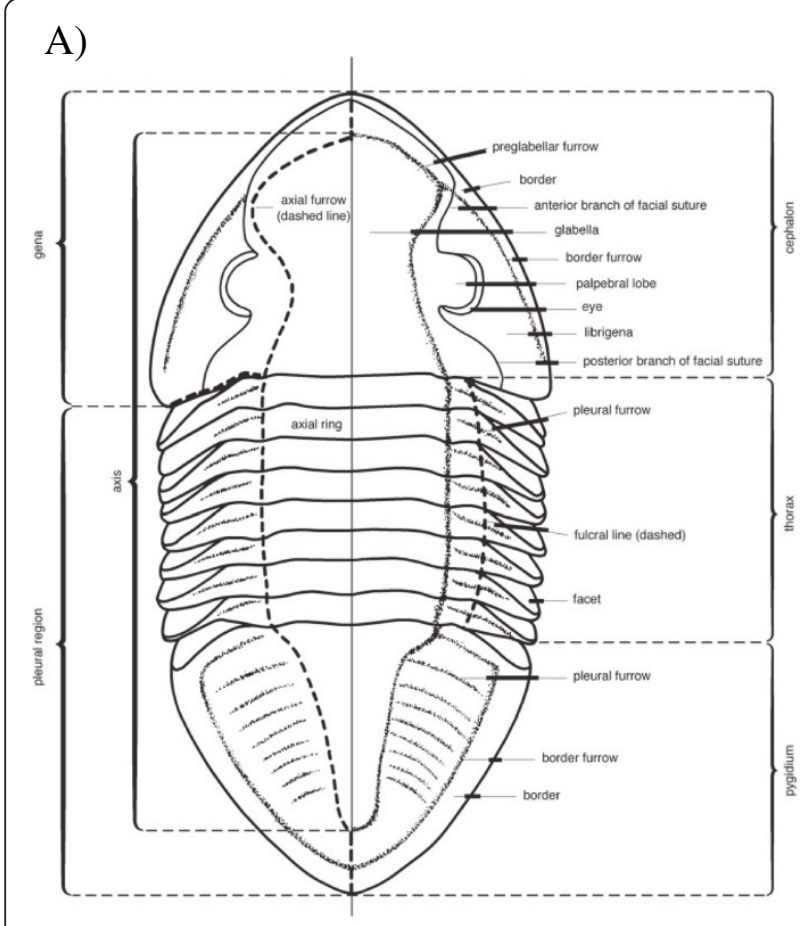

B)

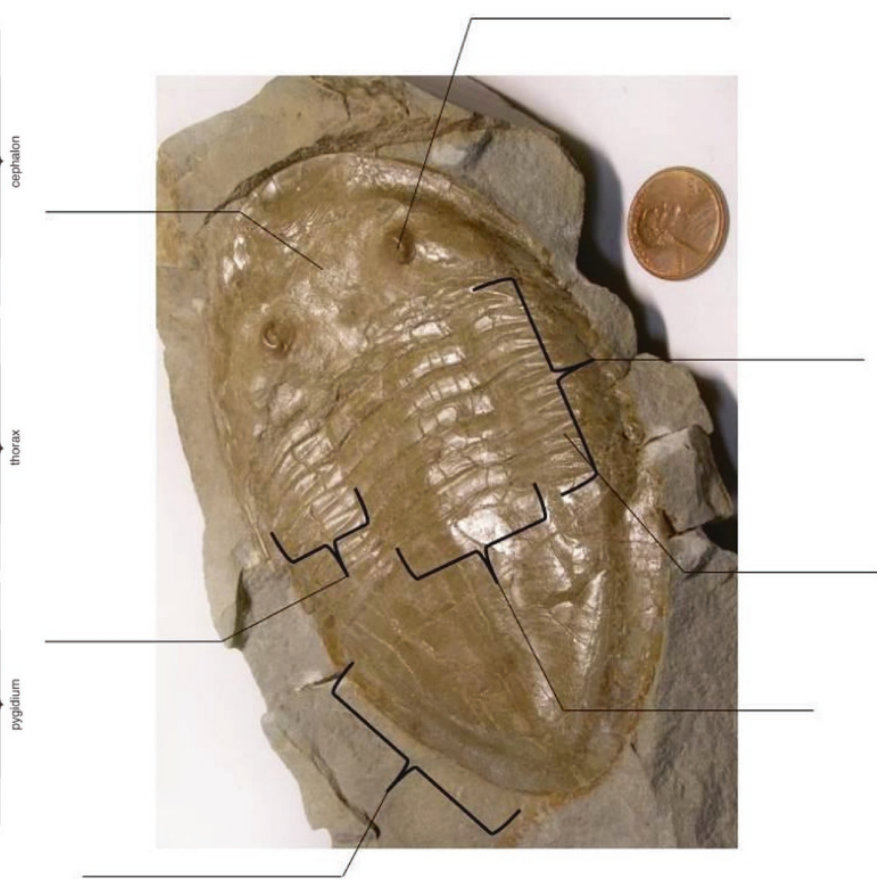

Figure 3 Additional diagram and specimen photo used to convey range in appearance of basic anatomy. A) Diagram of the Ordovician trilobite, Isotelus from the Treatise on Invertebrate Paleontology, used with permission. B) Isotelus iowensis. University of Kansas Museum of Invertebrate Paleontology (KUMIP) 294608. 
identifications on their own if necessary. This ability will negate the need to memorize systematic groups and help students hone a skill that they can transfer to other labs within a paleontology course or other courses in the natural and biological sciences. The simple fill-in-the-blank assessment used for this section allows for immediate feedback on students' grasp of the morphological terminology covered, so that professors can clarify points before moving on. Immediate application of the anatomical terminology reinforces the students' newly acquired knowledge and justifies why some terminology must be learned in order to discuss scientific questions, namely that differences in morphology are the evidence on which we base much of our scientific inquiry.

\section{Inferring organismal ecology using scientific reasoning}

As discussed above, with this lab students apply their newly acquired anatomical knowledge to consider the ecological lifestyles or niches of trilobites. This exercise is structured as a matching activity with a table of morphological characteristics and their ecological interpretations (Table 1), followed by a series of specimen photographs displaying a corresponding morphological feature (Figure 4). The layout of the table is purposefully reversed to model the scientific reasoning behind the information, rather than simply conveying information. The first column of the table lists examples of fossil evidence: morphological features, facies associations, or trace fossil evidence. The different types of evidence available are separated from their scientific interpretations. This distinction helps students to distinguish between primary and secondary interpretation of scientific evidence. The explicit separation of various types of evidence and interpretation gives professors an opportunity to discuss the role assumptions play in forming interpretations. Helping undergraduates master this distinction will help them evaluate scientific claims, comprehend scientific controversies, and construct better scientific arguments (Cross and Price 1991; Driver et al. 2000; Osborne 2010). The final column (Table 1) lists the scientific conclusion reached, in this case the mode of life ascribed to trilobites with a given morphology.

The study of ecological niches speaks to students' natural curiosity about how long extinct animals lived. This approach informs students about trilobite ecology from a knowledge acquisition perspective rather than rote memorization of details. Further, this set of examples aims to illustrate the relevance paleontology has when it comes to reconstructing past worlds and answering questions about ancient life using anatomy as evidence. In addition, this emphasis on how morphology can be used to make ecological inferences helps demonstrate to students why the small amount of anatomical information included in the laboratory is necessary to develop a common language with which scientists can approach larger scientific questions.

The matching portion of the exercise (Figure 4) provides another opportunity for students to apply their anatomical knowledge by critically examining specimen photos to recognize diagnostic features listed in the evidence column. The matching exercise allows professors to assess students' understanding of numerous anatomical concepts without overwhelming students with multiple in-depth questions. For instance, the professor may assess whether or not students understand what the phrase 'pitted fringe' means and if they can recognize one. Students will also be required to distinguish between dorsal and ventral views of specimens and recognize the hypostome. Matching rewards students for thinking critically as it allows them to eliminate possibilities. For example, students should be able to eliminate the possibility that the trilobites pictured in Figure $4 \mathrm{~B}$ and $\mathrm{E}$ were burrowers, given their long spines.

Table 1 Ecological niches of trilobites based on morphological or sedimentary evidence

\begin{tabular}{|c|c|c|}
\hline Fossil Evidence & Interpretation & $\begin{array}{l}\text { Inferred lifestyle } \\
\text { or behavior }\end{array}$ \\
\hline $\begin{array}{l}\text { Reduced thorax and pygidium; smoothed cephalon; } \\
\text { downward projecting spines; facies independence }\end{array}$ & $\begin{array}{l}\text { Light, streamlined body allows fast swimming. Spines prohibit effective } \\
\text { movement on the sediment surface. Distribution controlled by water } \\
\text { column characteristics rather than sediment characteristics. }\end{array}$ & $\begin{array}{l}\text { Pelagic lifestyle/ } \\
\text { swimming }\end{array}$ \\
\hline Smooth exterior, broad \& flat axial lobe & Reduce friction & Burrowing \\
\hline Larger muscle attachments & Stronger limb motions to move sediments & \\
\hline Eyes reduced or absent & Darker conditions, less need/no need for keen eyesight & Living in deep water \\
\hline Wide bodies, genal spines & Added support for soupy substrate & \\
\hline $\begin{array}{l}\text { Well-developed limbs, flexible hypostome, Cruziana } \\
\text { feeding traces }\end{array}$ & $\begin{array}{l}\text { Food passed anteriorly towards the mouth during the course of } \\
\text { movement, flexible hypostome used as a scoop. }\end{array}$ & Particle feeding \\
\hline Unusual occipital angle, pitted fringe & Pits allow water to flow through cephalon from leg-generated currents & Filter feeding \\
\hline $\begin{array}{l}\text { Rigid, strongly braced hypostome; forked } \\
\text { hypostome projections }\end{array}$ & Ability to process relatively large food particles & $\begin{array}{l}\text { Predatory, feeding } \\
\text { on soft bodied } \\
\text { worms }\end{array}$ \\
\hline
\end{tabular}




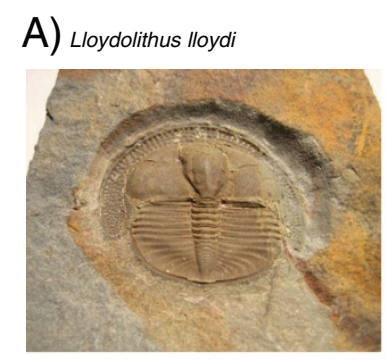

B) Carolinites genacinaca

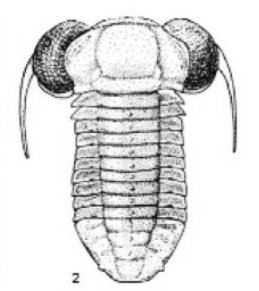

D) Cruziana trace fossil

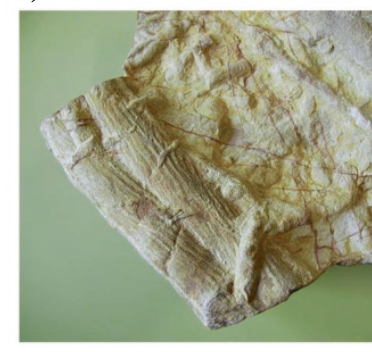

E) Ampyx priscus

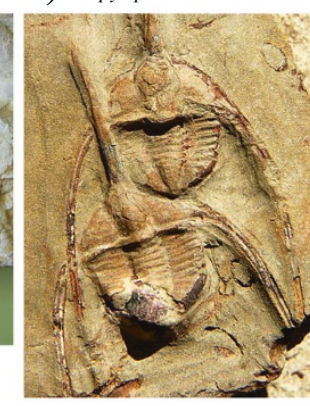

C) Asaphus lepidurus
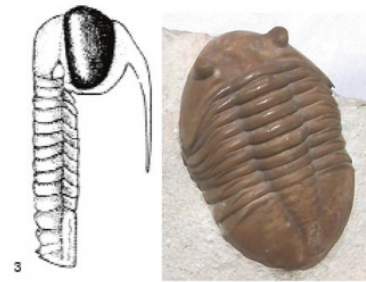

F) underside Asaphus expansus

Figure 4 Specimen photographs for ecological niche matching exercise. A) Lloydolithus lloydi, by Tomleetaiwan (Own work) [CCO], via Wikimedia Commons, B) Carolinites genacinaca, from the Treatise on Invertebrate Paleontology, used with permission, C) Asaphus lepidurus, by DanieICD (Own work) [CC-BY-SA-3.0 (http://creativecommons.org/licenses/by-sa/3.0)], via Wikimedia Commons, D) Cruziana trace fossil, by Luis Fernández García (Own Work) [CC-BY-SA-2.1-Es (http://creativecommons.org/licenses/by-sa/2.1/es/deed.en)], via Wikimedia Commons, E) Ampyx priscus, by Dwergenpaartje (Own work) [CC-BY-SA-3.0 (http://creativecommons.org/licenses/by-sa/3.0)], via Wikimedia Commons, F) Ventral view of Asaphus expansus, by Dwergenpaartje (Own work) [CC-BY-SA-3.0 (http://creativecommons.org/licenses/by-sa/3.0)], via Wikimedia Commons.

\section{Trends/events in the evolutionary history of trilobites}

Students, especially those with a background in biology, have frequently requested more information summarizing the evolutionary history of the fossil groups they were studying. This can be quite challenging when teaching students about taxonomic groups with which you are only marginally familiar. This lab utilizes recent scientific publications on intriguing trends in trilobite evolution to provide this information to both teachers and students who may not be particularly familiar with the Trilobita. The following example is an excerpt from the Spatial and Temporal Distribution section summarizing the biogeographic history of the clade.

The earliest trilobites appear suddenly in rocks of Early Cambrian age (522-530 Ma) from present day Scandinavia and eastern Europe. Soon afterwards trilobites also appeared in China, North America, Antarctica, and Australia and within the Early Cambrian are found throughout the world. The early history of trilobite evolution shows a pattern of biogeographic differentiation which taken with other evidence suggests that there may have been some significant period of trilobite evolution before they actually appeared in the fossil record. Current estimates suggest that although the earliest trilobites appeared in the fossil record around $525 \mathrm{Ma}$ they may have originated 550-600 Ma (Lieberman and Karim 2010). Paleontologists continue to investigate this trend looking for evidence of older trilobites and working to better constrain the timing of their origins. The reasons why the earliest relatives may have been absent from the fossil record remain unclear but may include the fact that they were small, lacked a hard shell, or they were very rare and restricted to environments where they were unlikely to fossilize.

Another example is the following excerpt from the same section that summarizes the history of trilobite diversification.

The trilobites continued to diversify into the Ordovician, but were hit particularly hard by the end Ordovician mass extinction. Trilobites were able to partially recover after the end Ordovician mass extinction, only to be hit again by the Late Devonian mass extinction. Trilobite diversity failed to rebound after the Late Devonian event and the group was eventually wiped out during the largest mass extinction of all time at the end of the Permian. Indeed, as we will discuss in more detail below, scientists are exploring the possibility that part of the reason trilobites are no longer with us today has to do with the fact that they fared particularly poorly during times of mass extinction (Lieberman and Melott 2013).

These passages introduce fossil patterns scientists are still actively studying and trying to explain. By highlighting areas of ongoing research, we hope to avoid the all-too-common impression among undergraduates that 
everything we wish to know about a certain group has already been discovered.

\section{Macroevolution: a case study}

Macroevolution often provides the best refutation of creationist arguments (Padian 2010). By contrast, creationists tend to accept the validity of microevolutionary patterns, arguing they only involve minor variations within set forms. This laboratory exercise allows paleontology professors to increase their coverage of macroevolution, as Padian (2008; 2010) suggested, without increasing the total number of laboratory assignments or sacrificing other worthy topics. By using trilobites as a macroevolutionary case study, this laboratory aims to cover both the fundamentals of a diverse taxonomic group (trilobites) and the broader concept of macroevolution. The Macroevolution of the Trilobites section begins with a general discussion of macroevolution, its patterns (Figure 5), and questions of interest to scientists. The following excerpt comes from the first paragraph of the Macroevolution section:

Macroevolution is the study of the patterns and processes that affect the birth, death, and persistence of species. For instance, scientists who study macroevolution might wonder when and why new species arise or why some groups speciate rapidly while others give rise to new species very slowly. Ultimately, macroevolution is the study of evolution at the grand scale and this is an area studied by paleontologists, evolutionary biologists, and systematists. Examples of macroevolutionary patterns include: similar changes in trait evolution across multiple groups within a given lineage and pulses of evolution in response to climate change (Vrba 1995; Congreve 2013).

The Macroevolution of the Trilobites section goes on to describe a specific trend in trilobite evolution based on the recent literature. "For example, the trilobites appear to be harder hit by mass extinctions than their contemporaries (Lieberman and Karim 2010). In spite of their high levels of diversity, trilobites suffered major losses during the end Ordovician (Melott et al., 2004) and Late Devonian mass extinctions (McGhee 1996). After the Late Devonian biodiversity crisis, trilobite diversity failed to fully recover (Brezinski 1999) and the group was wiped out completely during the largest mass extinction of all time at the end of the Permian (Fortey and Owens 1997)". The description of this trend leads naturally to the question, "Why do the trilobites thrive in normal background conditions yet remain more susceptible to mass extinctions than other types of organisms?"

To help students explore this question, the laboratory introduces and defines the concepts of extinction, origination, background extinction, mass extinction, and volatility. Volatility is defined in the exercise as a measure of a group's stability through time and, therefore, as a function of background rates of origination and

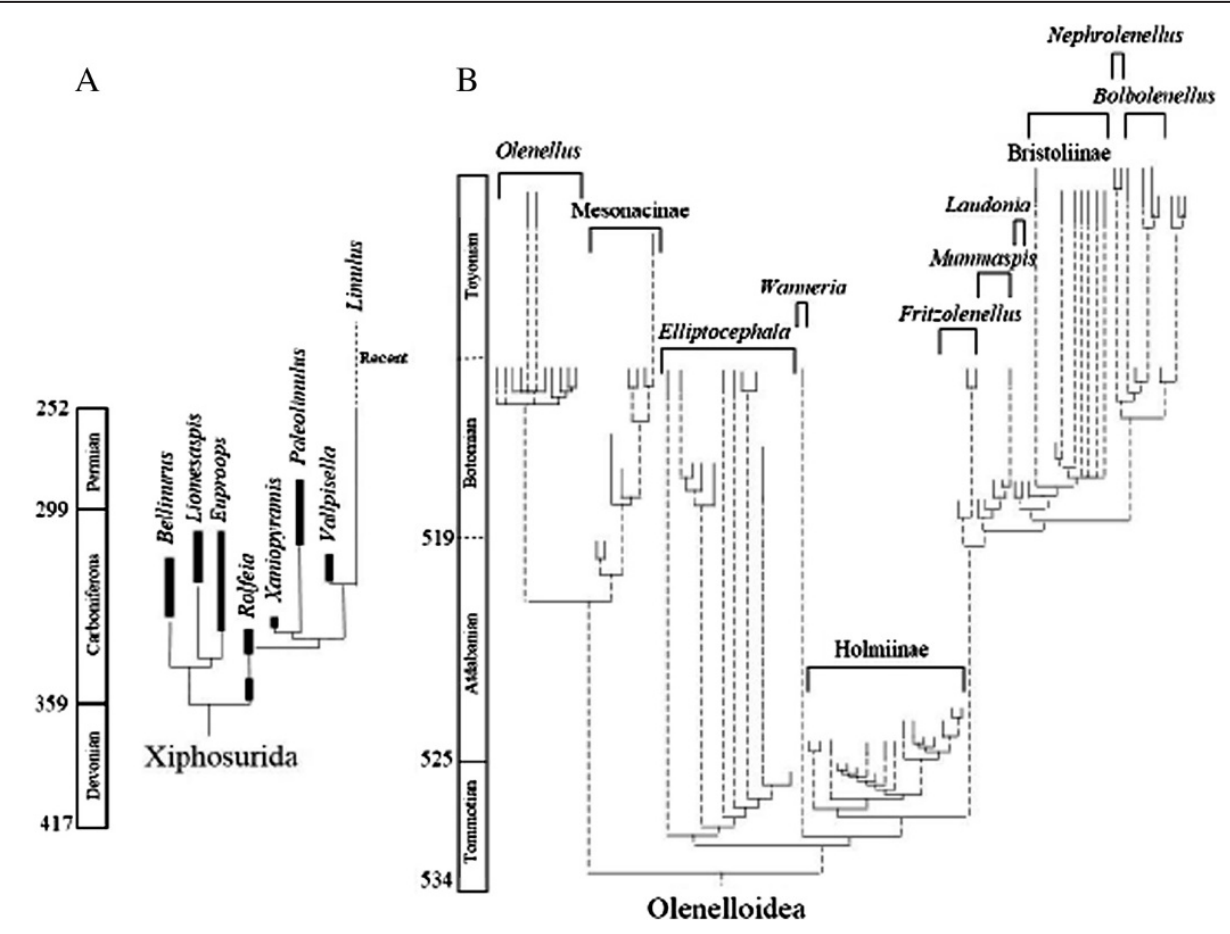

Figure 5 Phylogenetic relationships plotted against geologic time on the $y$-axis for A) the Xiphosurida (horseshoe crabs) modified after Anderson and Selden (1997), with permission from John Wiley and Sons, license 3326071282933; and B) the trilobite superfamily Olenelloidea from Lieberman (1999), copyright Yale University. 
extinction. The laboratory goes on to discuss the concept of volatility as it relates to trilobites and the question posed above.

High volatility clades have high rates of background extinction and origination, which can lead to the frequent turnover of species within the group. Low volatility groups have low rates of origination and extinction, leading to a stable clade made up of the same species over long periods of time. Volatility has been decreasing across all taxa throughout the Phanerozoic because high volatility groups have an increased probability of their diversity falling to zero, a value from which they can never recover (Lieberman and Melott 2013). Lieberman and Melott (2013) describe this increased risk of cladewide extinction as resulting in a "survival of the blandest" pattern as high volatility clades are weeded out over time while low volatility clades persist. The impacts of volatility seem to be particularly important during times of mass extinction, with high volatility clades, like ammonites and trilobites, suffering greater losses than their low-volatility contemporaries (Lieberman and Karim 2010). Interestingly, the reason trilobites, and also ammonites are no longer with us today, is likely because they evolved rapidly. It was the same factors that made them evolve rapidly, however, that made them prone to extinction.

Next the laboratory describes an analogy between volatility as it applies to paleontology and volatility in the stock market. This analogy will aid student understanding and retention by connecting the new information to the student's existing framework of knowledge (DeHaan 2005) and relating abstract principles to something students are familiar with in their daily lives. "In this analogy, stock market volatility is a measure of how a stock changes price relative to changes in the market as a whole. High volatility stocks are those that experience dramatic increases or decreases in price unpredicted by the greater market trend, while low volatility stocks are more likely to change their price congruently with the overall market trend. Research has shown that low volatility stocks yield the best returns for long-term investors; adjusting for inflation, an initial \$1 investment in 1968 yields $\$ 10.28$ in 2008 if invested in low volatility stocks and only $\$ 0.64$ if invested in high volatility stocks (from Baker et al. 2011)".

Once students have a theoretical understanding of volatility, the laboratory asks questions based on a real-world arthropod example (Figure 5) consisting of a high volatility clade (olenelloid trilobites) and a low volatility clade (horseshoe crabs). This example provides a visual representation of the patterns described in the text. This example and series of questions models to students how science is driven, in part, by the desire to explain intriguing patterns found in nature. An important extension of this type of modelling is the demonstration that while a scientific explanation may be proven false, the pattern itself is real and cannot be refuted nor adequately explained by creationist rhetoric. Questions include: "Which group has the highest rates of extinction over time?"; "Which group is the most stable (least volatile)?"; and "Based on the above readings, which group do you expect to have survived the longest? Explain your choice". These questions allow professors to assess students' tree-reading ability as well as their understanding of the new concepts covered in this exercise. The exercise concludes by requiring students to take a more active role and draw their own high volatility and

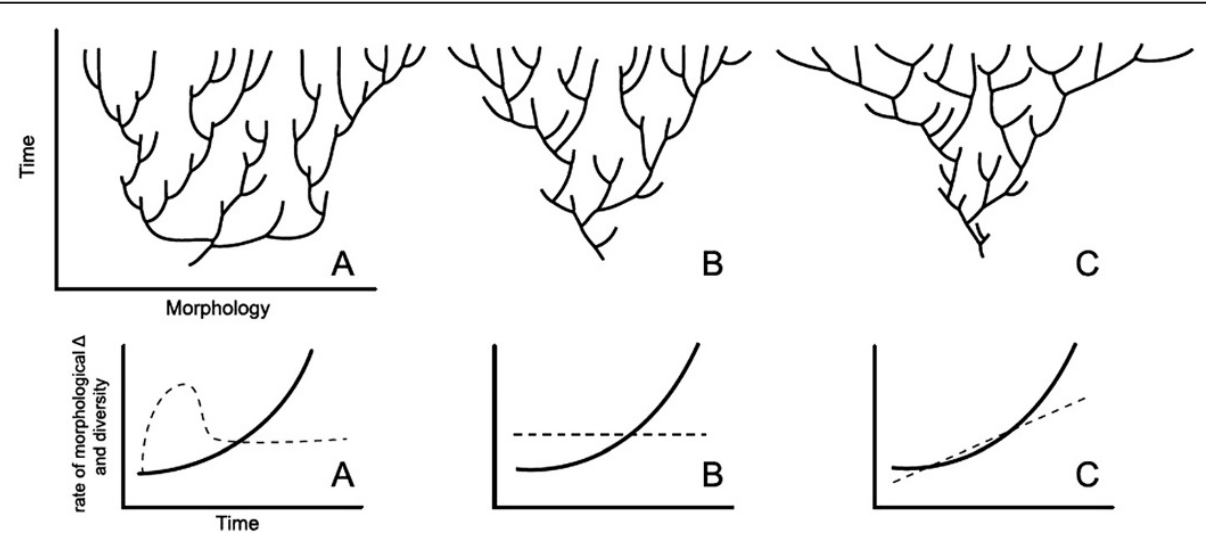

Figure 6 Schematic representations of lineage evolution with varied rates of morphological change and diversity increase. The bottom graphs show the relationship between time and rates of morphological change (the dashed line) and diversity increase (the solid line). The top row of graphs shows the number of species (number of branches) present at any given time (along the $y$-axis) and the range of morphologies represented by those species (width along the $x$-axis). All three scenarios (A, B, and C) show increasing diversity over time. In case $A$, the rate of morphological change peaks early and then returns to an average rate (dashed line). This is reflected in the corresponding tree that has similar widths (range of morphologies present) at the bottom (early in the clade's history) and the top (late in the clade's history). Reproduced from Abe and Lieberman (2012), copyright The Paleontological Society. 
low volatility trees using Figure 6 as a guide. This activity forces the students to think about the longevity of species (length of branches), number of branches, and the relationship between diversity and morphological disparity (width of tree) as they relate to the formation of their hypothetical high and low volatility clades.

Finally, macroevolutionary inquiries combine many different types of paleontological evidence and could therefore be used to great advantage as a linking concept or larger framework (DeHaan 2005) in a paleontology course. This particular exercise draws on tree thinking or tree reading skills that students would have already developed as well as the concepts of background extinction versus mass extinctions. Additional themes that could be investigated under the umbrella of their relevance to the study of macroevolution include: stratigraphic correlation and dating, phylogentics and systematics, biogeography, data gaps or biases (temporal or spatial), ecological roles or niches, environmental reconstruction, or climate reconstruction and cyclicity. A macroevolutionary framework could be incorporated into a class formally by introducing a new macroevolutionary question each week, and then exploring the new source(s) of data necessary to evaluate that week's line of inquiry. Use of macroevolution as a framework could also be introduced into the course less formally if so desired by linking concepts back to their relevance for addressing macroevolutionary questions in the course discussion of each specific topic. Regardless, this laboratory exercise will prove useful both in the context of a larger macroevolutionary framework or as a stand-alone exercise in a more traditionally structured paleontology course.

\section{Conclusions}

As this laboratory exercise hopefully becomes broadly utilized at various colleges we hope to gather data on its ease of use and efficacy. This publication (and distribution of the lab through the SERC educational website http://serc. carleton.edu/NAGTWorkshops/paleo/activities/79291.html, the PaleoNet listserv, the Trilogenetics website, and the new University of Kansas Invertebrate Paleontology Division's website) will provide the needed exposure to alert professors to its availability. We are especially interested in testing the validity of the approach that emphasizes a combination of macroevolutionary concepts in conjunction with the presentation of a relatively limited suite of anatomical terms and taxonomic detail (yet still enough of the two latter to make the exercise specimen based). Ultimately, we and others (e.g., Padian, 2008 2010) feel that a macroevolutionary discussion provides the best pedagogical approach for students and professors. However, like any hypothesis, validation will come from data derived from the users, both professors and students. Initial student response to the lab has been positive, with students noting in most cases that they particularly liked the pictures and illustrations. Many people were struck by the morphological variety attained by trilobites and their range in body size. One student noted, "There were trilobites as big as umbrellas (!!!!)". Students also remembered the volatility and mass extinction discussion and at least one student's survey response indicated that "the stock market and extinctions" portion was his/her favorite part of the lab. We suspect that in the long-term the use of such on line laboratory exercises will grow, as many college students have a strong interest in paleontology, yet few universities actually have the physical specimens in their collections to facilitate development of a lab exercise in paleontology. Further, we are currently working to modify this lab for middle school and high school audiences with the help of a junior high Earth Science teacher. In the future we hope to develop additional university-level labs on other key invertebrate fossil taxa such as brachiopods, mollusks, echinoderms, etc., using the same specimen-based approach focusing on ecology and evolutionary trends rather than memorization.

\section{Additional files}

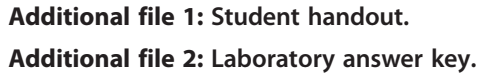

\section{Competing interests}

The authors declare that they have no competing interests.

\section{Authors' contributions}

MC drafted the manuscript and participated in its design. BL conceived of the study, participated in its design, and critically reviewed the manuscript. Both authors read and approved the final manuscript.

\section{Acknowledgements}

We would like to thank Una Farrell, Bruce Scherting, and Greg Ornay for help with KU exhibit specimens and two anonymous reviewers for thoughtful comments and suggestions. Financial support for making this lab was provided by NSF DEB 1256993 and EF 1206757

\section{Author details}

${ }^{1}$ Biodiversity Institute, Natural History Museum, University of Kansas, Lawrence, KS 66045, USA. ²Department of Ecology and Evolutionary Biology, University of Kansas, Lawrence, KS 66045, USA.

Received: 9 April 2014 Accepted: 4 August 2014

Published online: 22 August 2014

\section{References}

Abe, F. R., \& Lieberman, B. S. (2012). Quantifying morphological change during and evolutionary radiation of Devonian trilobites. Paleobiology, 38, 292-307. Anderson, L. I., \& Selden, P. A. (1997). Opisthosomal fusion and phylogeny of Palaeozoic Xiphosura. Lethaia, 30, 19-31.

Baker, M., Bradley, B., \& Wurgler, J. (2011). Benchmarks as limits to arbitrage: understanding the low-volatility anomaly. Financial Analysts Journal, 67, 40-54.

Brezinski, D. K. (1999). The rise and fall of late Paleozoic trilobites of the United States. Journal of Paleontology, 73, 164-175.

Congreve, C. R. (2013). Cladal turnover: the end Ordovician as a large-scale analogue of species turnover. Palaeontology, 56, 1285-1296.

Cross, R., \& Price, R. (1991). Towards teaching science for social responsibility: an examination of flaws in science, technology and society. Research in Science Education, 21(1), 47-54. (2013). doi:10.1007/BF02360456. 
DeHaan, R. L. (2005). The impending revolution in undergraduate science education. Journal of Science Education and Technology, 14, 253-269.

Driver, R., Newton, P., \& Osborne, J. (2000). Establishing the norms of scientific argumentation in classrooms. Science education, 84(3), 287-312.

Fortey, R. A., \& Owens, R. M. (1997). Evolutionary history. In R. L. Kaesler (Ed.), Treatise on Invertebrate Paleontology, O (Arthropoda 1, Trilobita, Revised) (pp. 249-287). Lawrence, KS: Geological Society of America and University of Kansas Press.

Lieberman, B. S. (1999). Systematic revision of the Olenelloidea (Trilobita, Cambrian). Bulletin of the Peabody Museum of Natural History, 45, 1-150.

Lieberman, B. S., \& Karim, T. S. (2010). Tracing the trilobite tree from the root to the tips: a model marriage of fossils and phylogeny. Arthropod Structure and Development, 39, 111-123.

Lieberman, B. S., \& Melott, A. L. (2013). Declining volatility, a general property of disparate systems: From fossils, to stocks, to the stars. Palaeontology, 56, 1297-1304.

McConnell, D. A., \& van Der Hoeven Kraft, K. J. (2011). Affective domain and student learning in the geosciences. Journal of Geoscience Education, $59,106-110$

McGhee, G. R. (1996). The Late Devonian Mass Extinction: The Frasnian/Famennian Crisis. New York, NY: Columbia University Press.

Melott, A. L., Lieberman, B. S., Laird, C. M., Martin, L. D., Medvedev, M. V., Thomas, B. C., et al. (2004). Did a gamma-ray burst initiate the late Ordovician mass extinction? International Journal of Astrobiology, 3, 55-61.

On the Cutting Edge - Professional Development for Geoscience Faculty. (2013). Teaching Paleontology In The 21st Century. http:/serc.carleton.edu/NAGTWorkshops/paleo/ index.html\#coursedesign. Accessed 18 December 2013.

Osborne, J. (2010). Arguing to learn in science: the role of collaborative, critical discourse. Science, 328(5977), 463-466. (2010). doi:10.1126/science.1183944.

Padian, K. (2008). Trickle-down evolution: an approach to getting major evolutionary adaptive changes into textbooks and curricula. Integrative and Comparative Biology, 48(2), 175-188.

Padian, K. (2010). How to win the evolution war: teach macroevolution! Evolution: Education and Outreach, 3(2), 206-214.

Vermunt, J. D., \& Vermetten, Y. J. (2004). Patterns in student learning: relationships between learning strategies, conceptions of learning and learning orientations. Educational Psychology Review, 16, 359-384.

Vrba, E. S. (1995). The Fossil Record Of African Antelopes (Mammalia, Bovidae) In Relation To Human Evolution And Paleoclimate (pp. 385-424). In E. S. Vrba, G. H. Denton, T. C. Partridge, \& L. H. Burckle (Eds.), Paleoclimate and Evolution with Emphasis on Human Origins. New Haven, CT: Yale University Press.

Weissert, W. (2013). Evolution Debate Again Engulfs Texas Board of Ed. AP. http://bigstory.ap.org/article/evolution-debate-again-engulfs-texas-board-ed. Accessed 10 January 2013

doi:10.1186/s12052-014-0020-5

Cite this article as: Casey and Lieberman: Beyond memorization: an intermediate-level paleontology activity that integrates anatomy, ecology, and macroevolutionary theory using trilobites. Evolution: Education and Outreach 2014 7:20.

\section{Submit your manuscript to a SpringerOpen ${ }^{\circ}$ journal and benefit from:}

- Convenient online submission

- Rigorous peer review

- Immediate publication on acceptance

- Open access: articles freely available online

- High visibility within the field

- Retaining the copyright to your article

Submit your next manuscript at $\gg$ springeropen.com 